\title{
How economics students are prepared for employment
}

\section{(based on the alumni and employer surveys and subject benchmark)}

The Economics Network conducts regular surveys to research the current state of teaching and learning in Economics Higher Education in the UK. These surveys are part of a comprehensive research programme, which aims to better understand the needs of our different stakeholders including students, lecturers, alumni and employers. They inform our support role and give a voice to the Economics community.

The results of past surveys can be seen on http://www.economicsnetwork.ac.uk/projects/surveys.htm

This paper will discuss how economics graduates are prepared for employment based on the results of the alumni and employer surveys and benchmark statement.

\section{Employers survey}

The employers study was prompted by concerns as to whether the (revised) Benchmark Statement for Economics reflects the full range of skills and knowledge required by employers, and also whether it takes account of the developing HE teaching and learning environment with new obligations such as PDP and employability initiatives.

In general the results indicate that the Benchmark Statement is appropriate for employers. The employers survey response suggests that 'debating skills' are not a core requirement since only around $30 \%$ of respondents deemed this Essential or Important. However, knowledge of 'developments in economic policy' did appear as Critical or Very Important to a significant number of respondents.

The main concerns raised in the survey were in terms of application of knowledge to problem-solving processes, communication skills and employability skills of the economics graduates.

Among the comments: "I have a real concern that too narrow a set of theories and models is taught in top UK universities and that opportunities to help students develop a better understanding of the world are missed;" "Some economics graduates we have recruited have had poor writing skills. This includes not being able to think clearly through an issue, structure a report and identify key conclusions;" "It's the quality of the writing, it's the accuracy ... you know a number doesn't mean anything unless you've got the source, year and context."

These comments are also relevant to the recruitment and employability issue where respondents indicated that failure to adhere to the application format and to submit applications without errors was disappointing.

The proportion of employers considering the skills brought to employment by Economics graduates to be 'excellent' or 'strong' varies widely by type of skill and knowledge (see Tables A1 and A2 ).

The range for skills is from 33\% (debating) to nearly 87\% (manipulation of quantitative data) with nearly half of the identified skills being scored at $>60 \%$. 
The range for knowledge is much narrower with figures from 29\% (development of economic policy) to nearly 53\% (opportunity cost). In general, less than half of respondents considered Economics graduates to be 'excellent' or 'strong' in any of the identified knowledge areas.

Table A1 Skills

\begin{tabular}{|l|c|c|}
\hline Skill type & $\begin{array}{c}\text { \% essential or } \\
\text { important } \\
\text { required skill }\end{array}$ & $\begin{array}{c}\text { \% excellent or } \\
\text { strong } \\
\text { achieved skill }\end{array}$ \\
\hline Work as team & 97.5 & 78.9 \\
Communicate clearly in writing & 97.4 & 55.3 \\
Communicate clearly in speech & 92.3 & 65.9 \\
Be objective & 90.0 & 73.7 \\
Organise/interpret/present quantitative data & 89.7 & 86.8 \\
Communicate complex concepts & 84.2 & 44.4 \\
Apply to real world & 82.5 & 60.5 \\
Apply knowledge & 79.5 & 82.9 \\
Deal with complexity & 76.9 & 56.8 \\
Locate principal information sources & 76.3 & 73.0 \\
Solve complex problems & 71.8 & 58.3 \\
Abstract (balance simplification and & 71.8 & 41.7 \\
relevance) & & \\
Use IT effectively & 71.1 & 83.8 \\
Research independently & 69.2 & 68.4 \\
Use diagrams appropriately & 64.1 & 45.7 \\
Build/use models & 61.5 & 59.5 \\
Sensitive to social/cultural/political issues & 61.5 & 56.8 \\
Strategic and means to ends & 60.5 & 45.9 \\
Debating skills & 30.0 & 33.3 \\
\hline
\end{tabular}

Note: Percentages refer to \% of valid responses for each skill taken separately.

Table A2 Knowledge

\begin{tabular}{|l|c|c|}
\hline Knowledge type & $\begin{array}{c}\text { \% critical or very } \\
\text { important } \\
\text { required knowledge }\end{array}$ & $\begin{array}{c}\text { \% excellent or strong } \\
\text { achieved knowledge }\end{array}$ \\
\hline Incentives and their effects & 54.1 & 47.1 \\
Interdependency of markets and & 52.8 & 35.3 \\
welfare & 51.4 & 44.1 \\
Inter-connections & 51.4 & 41.9 \\
Microeconomics & 45.9 & 42.4 \\
Social costs and benefits & 44.4 & 29.4 \\
Developments in policy and relevance & 44.4 & 39.4 \\
Marginal considerations & 43.2 & 32.4 \\
Impact of expectations and surprises & 40.5 & 52.9 \\
Opportunity cost & 37.1 & 32.4 \\
Macroeconomic variables and & 25.0 & 32.4 \\
relationships & & \\
Equilibrium, disequilibrium and stability & & \\
\hline
\end{tabular}

Note: Percentages refer to \% of valid responses for each knowledge item taken separately. 
An indicator of deficit has been based upon a comparison of the percentages of respondents giving the two highest ratings to importance (essential/important or critical/very important) and possession (excellent/strong). Concern may be felt if the proportion of respondents judging a skill/knowledge to be of high importance is not reflected in the proportion that consider Economics graduates to possess that skill/knowledge at a high level.

In general, both skills and knowledge appear to present many examples of deficit using this criterion.

Three skills which appear to require the most attention are abstraction, communication of complex concepts and communication in writing, although others are also apparent.

Deficits in knowledge are not so extreme, although this may in part be due to low expectations on behalf of employers. The two knowledge areas which stand out are developments in economic policy and interdependency of markets and economic welfare (along with, perhaps, impact of expectations and surprises).

Employers were very critical of Economics graduates' performance throughout the application and interview process. A lack of communication skills (both written and spoken) as well as inadequate preparation for the interview were remarked upon many times and given as reasons why applicants were either not given, or performed badly in, interviews. It would appear that some attention should be given to this aspect even though it may not be solely related to Economics graduates.

\section{Alumni survey}

We recognise that alumni can offer a unique perspective on evaluation of the skills and knowledge developed through a degree course and those required in the work place. To get information on how degree programs could be improved was one of the main purposes of our alumni survey.

When asked what was not included in the degree but would have been useful, alumni suggested specific modules, real world examples, work experience and work place skills. Many ask to learn about different schools of economic thought.

Abilities that were not well developed by their degree, according to a majority of respondents, include oral and written communication, fluency in using IT, general creative and imaginative powers and awareness of cross-cultural issues, indicating that these are areas that could be developed further.

When asked about skills they'd like to develop further, alumni mention econometrics and data analysis, application of theory to real life, communication and presentation skills.

A majority found all aspects of their course useful, when asked to mention the least useful aspects of their study. Some respondents mention courses not directly connected with their current employment.

They also suggested some areas where further development would bring rewards, including generic skills such as oral and written communication, and application of theory to real-world economic problems.

Their answers could be seen from the following chart: 


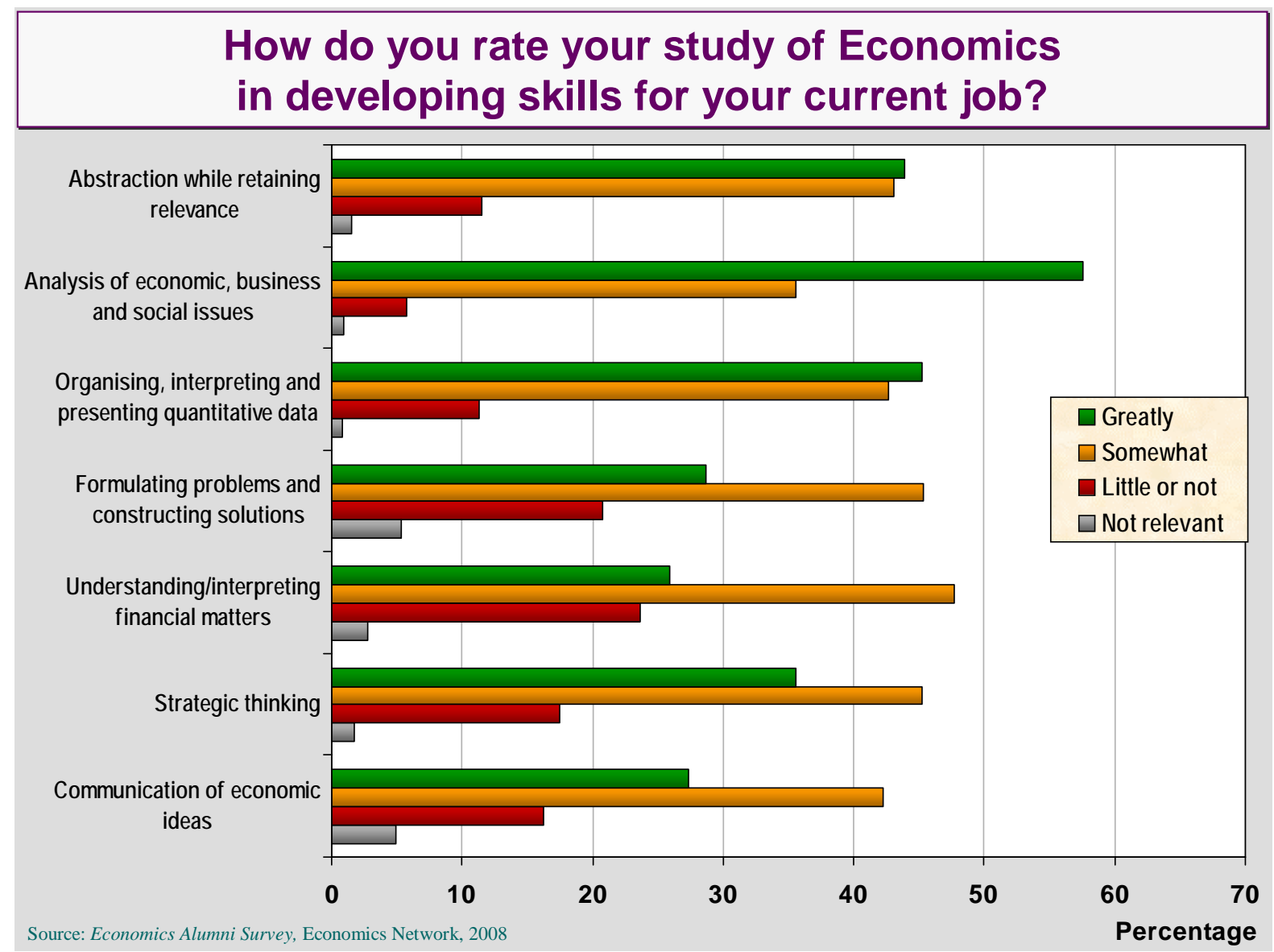

Comparing the results from 2004 and 2008 alumni surveys, the respondents' perception of the skills developed during their study has changed. In 2008 more respondents saw their skills developed to 'A great extent' then in 2004:

- Abstraction - $43.9 \%$ versus $39.2 \%$

- Analyses of economic...issues - $57.6 \%$ versus $52.1 \%$

- Ability to recognise...data $-45.2 \%$ versus $39.2 \%$

- Framing - $28.7 \%$ versus $19.0 \%$

- Communication of economic ideas - $36.7 \%$ versus $27.3 \%$.

At the same time some skills were perceived by graduates to be developed to a lesser degree in 2008 compared to 2004:

- Understanding and interpreting financial matters to 'A great extent' $25.9 \%$ versus $29.8 \%$

Strategic thinking $-35.6 \%$ versus $36.4 \%$.

We also ask alumni what skills help them get the current job.

Knowledge, degree and academic achievement along with communication and analytical skills were mentioned most often.

Some have specifically mentioned the ability to communicate with non-specialists 'A key criterion for economists working in government is to be able to convey complex economic issues to non-specialist audiences. My undergraduate degree did not consider this aspect of economics, though my masters did somewhat. You learn this a great deal on the job, but many people find this a stumbling block at interview'. 


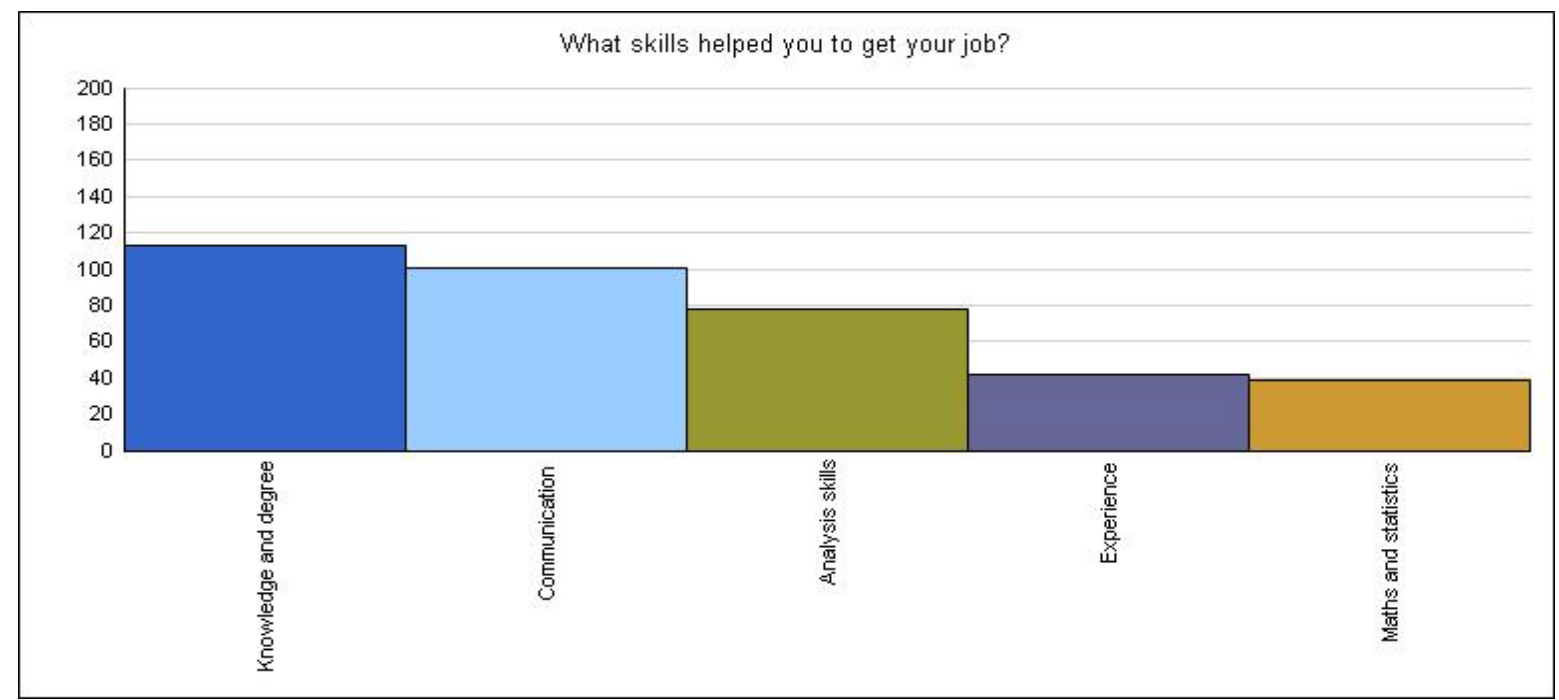

Increasingly employers are interested in graduates with generic as well as specialist skills. We ask respondents to rate contribution of their degree in respect of those skills.

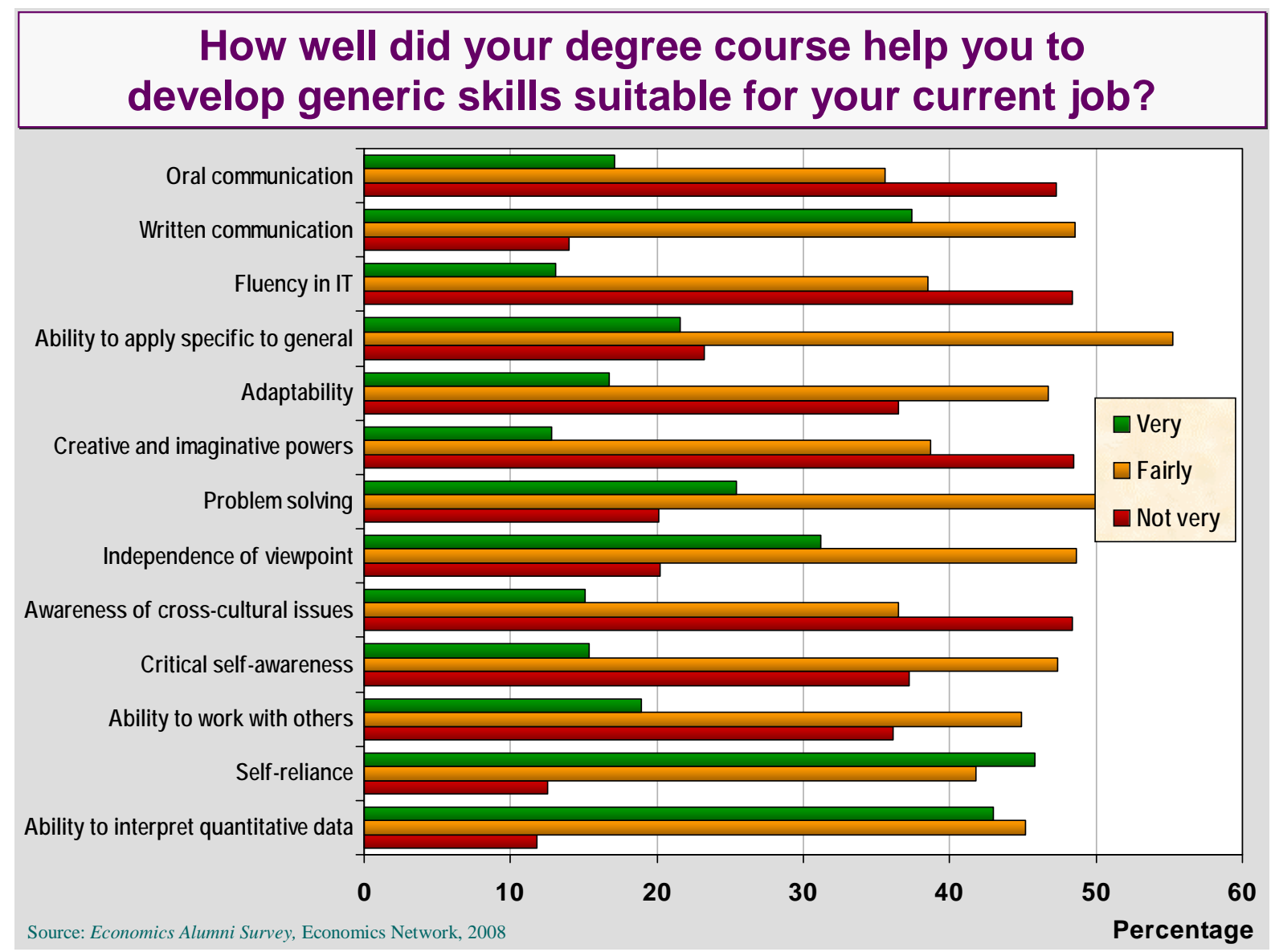

The majority of respondents rated the following as 'Not very high': contribution of their degree programme to the development of their ability for oral communication, fluency in using IT, general creative and imaginative powers and awareness of cross cultural issues as, indicating that these are areas that could be developed further. In 
comparison, the contribution of other skills listed was considered as "Fairly high", and only self-reliance was rated 'Very high' by respondents.

\section{Conclusions}

Many issues raised in both surveys are very similar. Both employers and economics graduates highly rated economics degree. Nearly two thirds of alumni offered their advice and encouragement to students considering taking an Economics degree. They praised the discipline, its role in the world and its value to the individual. They also suggested some areas where further development would bring rewards, including generic skills such as oral and written communication, and application of theory to real-world economic problems.

Employers mention their concern with the same issues: level of application of knowledge to problem-solving processes, communication skills and employability skills of the economics graduates.

Analysing common themes that emerge from employers and alumni surveys will allow us to better target our support to both lecturers and students. We hope that those surveys will not only provide the Economics community with useful information, but will play an important role in the improvement of teaching and learning in Economics. The Economics Network will be happy to provide workshops and advice to interested departments on the issues raised by any of the surveys. 